\title{
Optimization studies on turbidity removal from cosmetics wastewater using aluminum sulfate and blends of fishbone
}

\author{
Prosper E. Ovuoraye ${ }^{1} \cdot$ Victor I. Ugonabo ${ }^{1} \cdot$ Gina F. Nwokocha ${ }^{2}$
}

Received: 17 October 2020 / Accepted: 1 March 2021 / Published online: 22 March 2021

(c) The Author(s) 2021 OPEN

\begin{abstract}
This research is centered on the optimization of coagulation-flocculation treatment of cosmetic wastewater. It analyzes blends of fishbone (BFB) and aluminum-based coagulant (ABC) to determine the efficacy of BFB as a potential coagulant-flocculants aid at optimum conditions using response surface methodology (RSM). The experiment was carried out employing the standard nephelometric procedure at $1000 \mathrm{rpm}$ stirring rate. The central composite design (CCD) was used to examine the interactions of $\mathrm{pH}$, dosage, and settling time to maximize the turbidity removal efficiency of the $A B C$ - and BFB-driven coag-flocculation. The optimal pH, dosage, and settling time for $A B C$ were obtained as $10,0.1 \mathrm{~g} / \mathrm{L}$, and $2 \mathrm{~min}$, while $\mathrm{pH} 6,0.4 \mathrm{~g} / \mathrm{L}$, and settling time of $4 \mathrm{~min}$ were recorded for BFB following the established quadratic model of the RSM. The removal efficiency of ABC and BFB plots $80 \%$ and $88 \%$, respectively; this corresponds to 262 NTU and 288 NTU of removal from the wastewater at optimal conditions. The kinetics result indicated that the rate constant $\left(K_{\mathrm{f}}\right) 3 \times 10^{-3}(\mathrm{~L} / \mathrm{g} \mathrm{min})$ of BFB surpassed $5 \times 10^{-5}(\mathrm{~L} / \mathrm{g} \mathrm{min}$ ) recorded for $\mathrm{ABC}$ following second-order coag-flocculation reaction, with correlation coefficients $\left(R^{2}\right)$ values of 0.999 and 0.9985 , respectively. The research also applied cost-benefit analysis for the determination of the efficacy of BFB. The figure obtained shows that the benefit of using BFB will save $\$ 5.50$ compared to $A B C$ based on this work. At optimal conditions, $B F B$ satisfied the environmental protection agency $\mathrm{pH}$ standard for industrial wastewater discharge, promising coagulant-flocculants aid for industrial wastewater purification purpose and the preservation of the environment.
\end{abstract}

Keywords Blends of fishbone - Coagulant-flocculants aid - Cosmetics wastewater - Efficacy - Optimization - Kinetics · Alum · Environmental protection agency (EPA)

\section{Introduction}

Growing demand and usage of cosmetic products in recent times have spurred remarkable growth in the cosmetics production industry. Consumers of cosmetics products have been spending high levels of disposable income on cosmetics than they had in the past. According to report, global cosmetic products market was valued around $\$ 532$ billion in 2017 and is expected to reach approximately $\$ 863$ billion by $2024[1,2]$. The increasing consumption of cosmetic products for human beautification purposes has directly facilitated the increasing generation of wastewater associated with high turbidity and other contaminants from production sites $[1,3]$.

According to the environmental protection agency (EPA), turbidity in water should not exceed 40NTU [4]. The EPA guidelines also specified $\mathrm{pH}$ within (5.5-9) as standards for wastewater discharge $[5,6]$; hence, cosmetic

Supplementary Information The online version contains supplementary material available at https://doi.org/10.1007/s42452-021-04458y.

$\triangle$ Prosper E. Ovuoraye, foreman028@gmail.com | ${ }^{2}$ Department of Chemical Engineering, Nnamdi Azikiwe University, Awka, Nigeria. ${ }^{2} \mathrm{CCISS}$ Centre for Power Engineering Training Program, Calgary, AB, Canada. 
wastewater with turbidity contents greater than 250NTU is considered a point source pollutant. The level of contaminants present in wastewater poses serious industrial and environmental concerns. High turbidity promotes the growth of pathogens in water leading to waterborne disease outbreaks, which have caused significant cases of intestinal sickness $[4,7]$. It also reduces significantly the aesthetic quality of water, having very harmful impact on the water bodies when not disposed properly. Industrial effects of turbidity are not left out of concerns, as it contributes to clog tanks and pipes corrosion, eventually damaging them [8]. Also, turbidity in effluents and their complex characteristics pose severe resistance to unit operations which undergoes in industrial wastewater treatment plants $[4,7]$; hence, the importance of turbidity removal in wastewater treatment before discharge cannot be over emphasized.

There are different treatment processes applied to enhance the removal of contaminants from wastewater [9]. These processes includes coagulation and flocculation [10, 11], adsorption [8], and reverse oxidation [12] which was applied in recent times to remove bacterial from wastewater $[8,13,14]$. These are the most commonly sought-out treatment processes for the removal of turbidity from wastewater that contains significant amount of settle-able and suspended solids.

Handling high turbidity in wastewater is cost intensive, since the rising cost of purchasing conventional chemicals, energy required for treatment operations, and the adverse effect of inorganic chemicals on the environment have grown with the proportionate increase in pollution [15, 16]. However, the long-term application of some inorganic coagulants-flocculants has raised concerns associated with sludge, corrosion, and uncertainties regarding their environmental impacts $[10,15,17]$; to this end, organic materials are widely sorted as alternatives to synthesized chemicals previously used as coagulant-flocculants in water treatment processes. Also, most organic materials were applied as coagulants-flocculants aid for water treatments due to their ability to efficiently promote flocculation at optimum dosages and cost efficiency $[10,18]$.

Fisheries and aquaculture production is an important industry in a number of countries among the likes of Chile, India, Indonesia, Viet Nam, Bangladesh, Egypt, and Norway. China and Nigeria have consolidated their shares in regional or world production of fishery to varying degrees over the past two decades $[19,20]$. In 2018, world production attained another all-time record as high as 114.5 million tons in live weight [20]. The sector is also expected to expand the most in Africa up to $48 \%$ driven by the additional culturing capacity put in place in recent years for tilapia and catfish, respectively $[10,11]$. Asia will continue to dominate the aquaculture sector and will be responsible for more than $89 \%$ of the increase in production by 2030 [20]. These report reviews the possible availability of fishbone in surplus as raw material that can be harnessed and reused for any industrial and commercial purposes especially for industrial treatments of wastewater.

The works of references [21-23] reported that bones from fisheries and aquacultures possess high absorptive characteristics and were capable of inducing coagulation-flocculation exploited for the removal of contaminants from wastewater under varying operating conditions [9]. However, effective coagulation-flocculation for turbidity removal depends on a number of factors such as the compositions of the organic coagulant, the process variables, and equipment used. The conditions of experiment including the mixing rate, $\mathrm{pH}$ modifications, the concentration of the colloidal particles, acidity/alkalinity of the wastewater, and dosages of the organic coagulants are contributing factors toward achieving greater clarification efficiency $[9,10]$. The challenges of using organic coagulants still remain that fundamental background knowledge about their $\mathrm{pH}$ modifications, clarification efficacy, and interactions with the substrates in the water medium is often scarce, or insufficient to infer the best chemical configuration for treating a specific effluent $[9,24,25$, 4]. These challenges have grown with the proportionate increase in their inability to satisfy the EPA pH standards for wastewater discharge.

The present study investigated the efficacy of reuse waste materials, blends of fishbone (tilapia, salmon, and catfish) as coagulant-flocculants aid for the removal of high turbidity from cosmetic wastewater. The objectives of the research included the determination of the optimum operating conditions for the coag-flocculation treatment of the wastewater using RSM, and investigating the coag-flocculation kinetics model for the blends of fishbone and alum-driven coag-flocculation, in order to compare their rate constants which was applied as a criterion to determine the effectiveness of BFB at high mixing rate. The study also included the cost-benefits analysis of the process, to examine the efficacy of BFB over $A B C$ at optimal conditions, and to satisfy the EPA pH standards for wastewater discharge.

\section{Materials and methods}

\subsection{Materials}

The wastewater sample was collected from Emos Best Industries Nigeria Limited. The organic coagulant samples used for this work were obtained from reused waste materials consisting of dried fishbones which were received as a gift from local fish traders in the riverine area of the Niger 
Delta, the aim of ensuring the availability of the organic coagulant source.

\subsection{Preparation of the coagulant}

The organic coagulant consisted of fishbone samples from tilapia, salmon, and catfish weighing $5 \mathrm{~kg}$, was sun-dried for about 3 weeks, crushed, and ground to increase its surface area. The crushed samples were mixed thoroughly and screened through 20 mesh sizes to obtain flour of finer particles which were collected in a container ready for use. The blended fishbone coagulant was characterized at Pymok Research Laboratory Enugu, Nigeria.

The proximate analysis on the prepared organic coagulant sample was done at Spring Board Research Centre, Awka, Nigeria. The characterization and proximate analysis of the blended fishbone samples were carried out to ascertain the chemical constituents, compositions, and concentrations of the organic structure following the standard procedure in accordance with reference [15]. The results of the characterization and proximate analysis on blended fishbone (BFB) coagulant are presented in Table 1.

The conventional coagulant used in this work consisted of $2 \mathrm{~kg}$ of aluminum-based salt (Alum) of industrial grade has a chemical formula: $\mathrm{Al}_{2}\left(\mathrm{SO}_{4}\right)_{3} \cdot 18 \mathrm{H}_{2} \mathrm{O}$, molecular weight $(666.42 \mathrm{~g} / \mathrm{mol})$, made up of $51-59 \% \mathrm{Al}_{2}\left(\mathrm{SO}_{4}\right)_{3}$, with $\mathrm{pH}$ range (2.5-5.5) was bought from Kincel Excel International Nigeria Limited. The aluminum-based coagulant $(A B C)$ was ground to fine powdered form to increase the surface area of the coagulant. It was then stored in a separate container ready for use.

\subsection{Procedure}

The wastewater sampling was carried out at Halden Nigeria Limited, Port Harcourt, Nigeria. In the course of the experiment, the preserved sample of the cosmetics wastewater was characterized in accordance with the standard method of examination of wastewater as stated

Table 1 Characterization and proximate analysis of BFB coagulant

\begin{tabular}{llll}
\hline Constituents & Concentrations (g/L) & Compositions & $\begin{array}{l}\text { Per- } \\
\text { cent- } \\
\text { age } \\
(\%)\end{array}$ \\
\hline Calcium & 0.0404 & Protein & 4.3 \\
Iron & 0.02676 & Carbohydrate & 0.3 \\
Zinc & 0.00966 & Ash & 47 \\
Copper & 0.00052 & Fiber content & 37 \\
Manganese & 0.00032 & Crude Protein & 4.2 \\
Potassium & 0.002 & Moisture & 2.5 \\
Sodium & 0.001845 & Fat & 5.0 \\
\hline
\end{tabular}

in reference [15]. The standard nephelometric test was conducted on the wastewater samples. In the course of the treatment process, the initial turbidity (NTU) of the wastewater sample was measured and recorded. The $\mathrm{pH}$ of the solution was adjusted using $0.1 \mathrm{M} \mathrm{HCL}$ or $0.1 \mathrm{M}$ $\mathrm{NaOH}$ just before the measured doses of the coagulants $A B C$ and $B F B$ ranging from 0.1 to $0.5 \mathrm{~g} / L$ were, respectively, added. The mixing speed of $1000 \mathrm{rpm}$ was maintained for $10 \mathrm{~min}$ after which it was reduced to $250 \mathrm{rpm}$ for $20 \mathrm{~min}$ using a magnetic stirrer, while the settling time following the coag-flocculation treatment was varied from $2 \mathrm{~min}$ through $30 \mathrm{~min}$.

In the course of each experimental run, a pipette was used to draw samples for testing, and the corresponding turbidity (NTU) of each samples drawn was measured using the turbidity meter. The corresponding experimental results were used to calculate the percentage turbidity removal efficiency which served as the response parameter following the process optimization.

\subsection{Experimental conditions}

The $\mathrm{pH}$ was varied to $2,4,6,8$, and 10 , respectively, using a Delta-320 pH meter and dosage range between 0.1 and $0.5 \mathrm{~g} / \mathrm{L}$. The settling time was varied from $2 \mathrm{~min}$ through $30 \mathrm{~min}$, respectively, at room temperature and atmospheric pressure condition. The percentage turbidity removal efficiency was calculated by Eq. 1 .

$\% E=\frac{N_{0}-N_{t}}{N_{0}} \times 100$

where $N_{0}$ is the initial turbidity (NTU) content of wastewater sample before treatment, and $N_{t}$ is the turbidity content of the wastewater after treatment with blended fishbone and alum-based coagulant, respectively. The concentrations of the turbidity particles removed from the wastewater were evaluated by a multiplying factor of 2.35 $[10,11]$ as shown in Eq. 2 , where $C_{i}$ represents the concentrations $(\mathrm{g} / \mathrm{L})$ of the colloidal particles causing turbidity in the wastewater sample.

$C_{i}=2.35 \times N_{t}$.

\subsection{Experimental designs}

The central composite design (CCD) of the response surface methodology (RSM) was used for the optimization study. The CCD is an experimental design used for building a quadratic model for responses without the need to use a complete three-level factorial experimental design and provides information about interactions among experimental variables within the range studied, leading 
to better knowledge of the process. The CCD design was randomized but not replicated at each experimental condition [8]. The relationship between the coded values and the actual values is obtained by Eqs. 3 and 4 .

$X_{k}=2\left[\frac{X_{K}-X_{t}}{R}\right]$

where $x_{t}$ is the coded value, $X_{k}$ is the actual value of variable $k, X_{k}$ is the midpoint value of variable $k$, and $R$ is the range of variable $k$. The three levels of factors included the optimum values obtained from the RSM experimental runs and two other points that were within the experimented region but not values outside the experimental design matrix used for the central composite design.

$\propto=2^{\frac{n}{4}}$

The most common empirical models fit to the experimental data take either a linear, cubic, or a quadratic form, with the coefficients of the model used to establish the design model equations showing the relationship and interactions of the factors and their significance with the response.

\section{Results and discussion}

\subsection{Characteristics of the blends of fishbone}

The characterization result of BFB showed that the organic material contains varying proportions of calcium, iron, zinc, sodium, potassium, and magnesium presented in terms of their concentrations.

The result of the analysis confirmed that the structure of the organic material is predominantly made of calcium and iron in concentrations of $0.04044 \mathrm{~g} / \mathrm{L}$ and $0.02676 \mathrm{~g} / \mathrm{L}$, respectively, while zinc, sodium, and potassium were recorded in the amounts of $0.009 \mathrm{~g} / \mathrm{L}, 0.001 \mathrm{~g} / \mathrm{L}$, and $0.002 \mathrm{~g} / \mathrm{L}$. The copper and manganese contents in the structure of BFB were found in smaller volumes in concentrations lesser than $0.001 \mathrm{~g} / \mathrm{L}$. These results suggested that BFB is likely to be a natural metal-based organic coagulant. The blending of the different species of bones increased the alignments of the metal ions in reasonable proportions in the structure, thereby increasing the potential of BFB to induce coagulation when the positive-charged metallic ions are precipitated from the surface and diffuse into the water medium $[9,26,27,28]$.

However, the result of the proximate analysis carried out on the blends of fishbone shows that the powdered form of the organic coagulant contains low percentage of moisture recorded at $2.5 \%$ in value. Thus, we suggested that the powdered form of BFB is possibly hydrophilic
[29]. Also, 47\% ash content was reported for the organic coagulant. The blends of fishbone also contained $5 \%$ of carbohydrates, while the fiber contents were reported to be $37 \%$. Depending on the functional groups present in the structure of the organic material, we reasoned that the fiber contents may act as an integral part of the organic coagulant to producing better absorptive surfaces that can facilitate the absorption of contaminants in the water medium.

The protein and fat contents presented in BFB following the analysis were reported to be $4.3 \%$ and $5 \%$, respectively. The percentage of proteins in the BFB structure are indication of the presence of amino groups, with polymeric characteristics $[18,30]$, that are capable of promoting aggregation of colloidal particles during coagulation $[16,28,31]$. The result of the analysis for blended fishbone is shown in Table 2.

\subsection{Characteristics of the wastewater}

The result of the wastewater characteristics shows that total suspended solid (TSS) and total dissolve solid (TDS) contents of the water were recorded as $401 \mathrm{mg} / \mathrm{L}$ and $232 \mathrm{mg} / \mathrm{L}$, respectively. The biological oxygen demand (BOD) and chemical oxygen demand (COD) of the wastewater were reported to be less than $4 \mathrm{mg} / \mathrm{L}$. The wastewater sample collected from the industrial facility has a low acidity of $6.02 \mathrm{mg} / \mathrm{L}$. It has a high alkalinity of $134 \mathrm{mg} / \mathrm{L}$. The turbidity of the water was recorded as 350 NTU, at $\mathrm{pH}$ of 4.2. We can infer from the result in Table 2 that the wastewater is highly contaminated going by its characteristic, and it does not satisfy the EPA acceptable standards for wastewater discharge. Consequently, measures must be put in place to ensure the water is treated to satisfy the EPA standard for industrial wastewater discharge.

\subsection{Coagulation-flocculation process optimization and analysis}

The optimization of the coagulation-flocculation treatment of the cosmetics wastewater using blends fishbone (BFB) and alum-based coagulant (ABC) was carried out using the response surface methodology (RSM). The central composite design (CCD) was selected with zero block and used to build the quadratic model for 20 experimental runs to accommodate more interactions of the experimental factors $A=$ dosage $(\mathrm{g} / \mathrm{L}), B=\mathrm{pH}$, and $C=$ settling time ( min) as independent factors used for coag-flocculation optimization. The quality of the quadratic model was expressed by the coefficient of determination of $R^{2}$ value, and its statistical significance and the model adequacy were checked by the Fisher's $F$ value in the same program 
Table 2 Characteristics of the cosmetics wastewater sample

\begin{tabular}{llc}
\hline Wastewater & Methods used for analysis & Values \\
\hline $\mathrm{pH}$ & APHA 4500-H & 4.2 \\
Turbidity (NTU) & D1889 & 350 \\
Total dissolved solids, $\mathrm{mg} / \mathrm{L}$ & APHA 2540-C & 300 \\
Total suspended solids, $\mathrm{mg} / \mathrm{L}$ & APHA 2540-C & 402 \\
Acidity, $\mathrm{mg} / \mathrm{L}$ & ASTM D1067 & 6.02 \\
Alkalinity, $\mathrm{mg} / \mathrm{L}$ & APHA 2320-B & 134 \\
Chemical oxygen demand (BOD), $\mathrm{mg} / \mathrm{L}$ & APHA 5210-B \\
Biological oxygen demand (COD), mg/L & APHA 5220-D & 4.10 \\
Fecal coliform MPN/100 mg/L & APHA 9221B \& 9221C & $<3.5$ \\
Electrical conductivity, s/cm & APHA 2510 & \\
Total coliform MPN/100 mL & APHA 9221B \& 9221C & 804 \\
Free fatty acid, mg/L & $<1$ & \\
Hydroquinone, mg/L & $<1$ & \\
Total viable count, Cfu/mL & APHA 9221B \& 9221C & $4 \times 10^{2}$ \\
Fluorescent dissolved organic matter (FDOM) accounted & & Not \\
Colored dissolved organic matter (CDOM) accounted & & Not \\
\hline
\end{tabular}

using the trial version of the Design Expert Software version 12.0 .

Model terms were evaluated by the $p$ value (probability) with $95 \%$ confidence level. Three-dimensional surface plots and their respective contour plots were obtained for the BFB-driven and $A B C$-driven coag-flocculation treatment of cosmetic wastewater based on the effects of the three factors: dosage, $\mathrm{pH}$, and settling time at two levels. The quadratic model was selected with $p$ values less than 0.0500 indicated model terms are significant with the interactions of the three factors for BFB-driven and alumdriven coag-flocculation.

The coefficients estimated represent the expected changes in the response per unit change in the significant factor values when all other remaining factors are held constant. The intercept in an orthogonal design is the overall average response of all the runs. The coefficient of determination $R^{2}(0.9706)$ obtained shows that the degree of fitness confirms there is a very high correlation between the experimental responses and the predicted values of the factors. The correlation between the actual versus the predicted values of the response is presented in Fig. 1 of ESM. An Adjusted $R^{2}(0.9441)$ obtained with the analysis of variance is in reasonable agreement with the coefficient of correlation $R^{2}$ value of 0.9706 . The values of $R^{2}$ are close to unity and confirm the validity of the quadratic model used for the experimental design.

The analysis of variance (ANOVA) report for the experimental run of the BFB-driven coag-flocculation treatment is presented in Table 3 of ESM. A $p$ value less than 0.0500 with the model $F$ value of 36.68 indicated model terms are significant. In this case, $A, B, C, A B, B^{2}$, and $C^{2}$ are significant model terms. The predicted $R^{2}=0.7932$ is in reasonable agreement with the adjusted $R^{2}=0.9441$, i.e., the difference is less than 0.2 with a standard deviation of 4.46 . The model equation relating the response \%turbidity removal efficiency $(Y)$ and the interactions of the independent process variables: dosage $(A), \mathrm{pH}(B)$, and settling time $(C)$, for the BFB-driven coag-flocculation is represented by Eq. (5):

$$
\begin{aligned}
Y= & 83.40+17.88 A+11.72 B+4.88 C-12.85 A B \\
& -2.65 A C-0.85 B C-2.51 A^{2}+7.49 B^{2}-9.51 C^{2}
\end{aligned}
$$

The dosage of BFB was found to have the most significant influence on the response followed by the $\mathrm{pH}$ of the solution as observed from the respective coefficients of the model (Eq. 5). The interactions of the factors with their effects of the model terms on the response are ranked in the order:

$A>B>B^{2}>C>B C>A^{2}>A C>C^{2}$

However, the quadratic model terms for the $A B C$-driven coag-flocculation were evaluated at $95 \%$ confidence level. The quadratic model's $F$ value of 31.17 and $P$ value of 0.075 obtained following the central composite design indicated that the model terms $A, C, A^{2}, B^{2}$, and $C^{2}$ are significant. A lack of fit values of 4.05 obtained with the model was greater than 0.1000 which indicated that the lack of fit is not significant. The interactions of the model terms with their significant effects on the response are in the order:

$B 2>A 2>C>A B>A C>B>B C>A>C 2$

The quadratic model developed for $A B C$ follows that the dosage $(\mathrm{g} / \mathrm{L})$ has the most significant effects on the turbidity removal efficiency, followed by the $\mathrm{pH}$ of the solution. The coefficient of determination $R^{2}(0.9706)$ 
obtained for the model with the degree of fitness confirms there is a very high correlation between the experimental responses and the predicted values of the factors. The correlation between the actual versus the predicted values of the response for $A B C$-driven coagulation is presented in Fig. 4 of ESM.

However, the model fit statistics shows that the predicted $R^{2}(0.8211)$ and the adjusted $R^{2}(0.9346)$ have a difference less than 0.2 and are in reasonable agreement with the correlation coefficient $R^{2}$ value of 0.9656 . These statistical values are close to unity and plot a linear correlation between the actual value and the predicted values of the response as shown in Fig. 2 of ESM. An adequacy precision value of 22.716 which measures the signal-tonoise ratio indicated a ratio greater than 4 ; hence, there is an adequate signal ratio with the quadratic model established for ABC-driven coagulation-flocculation optimization process.

The final quadratic model equation in terms of experimental factors ( $\mathrm{pH}$, dosage, and settling time) that were used to make predictions about the percentage turbidity removal efficiency $(Y)$ at given levels of each factor for the ABC-driven coag-flocculation is given by Eq. 6 .

$$
\begin{aligned}
Y= & 40.8909-2.9 A+1.6 B-17 C+A B+1.75 A C \\
& -2.25 B C+7.773 A^{2}+13.27 B^{2}-6.72 C^{2} .
\end{aligned}
$$

The optimal results for the $A B C$ - and BFB-driven coagulation-flocculation treatment of the cosmetic wastewater were determined based on the interpretation of the solution to the final model Eqs. 5 and 6, respectively, from Design Expert Software version 12.0. The optimization goal for factors: dosage, $\mathrm{pH}$, and setting time, was maintained within the range of experimental data with the objective of maximizing the response \%turbidity removal efficiency.

The ramp plots presented in Figs. 3 and 4 of ESM were obtained at a desirability of 1.0. The plots also show predicted values of the output responses which corresponds to the optimal points located within the range of experimental design boundary. These points are represented by the depth, data components, and the intensity of the colors gradients of the surface and contour plots. They confirm the optimal results for the BFB- and ABC-driven coagulation-flocculation treatment processes.

\subsection{Optimization results for $A B C$ and BFB coag- flocculation}

The optimal $\mathrm{pH}$, dosage, and settling time were recorded as $6,0.4 \mathrm{~g} / \mathrm{L}$, and $4 \mathrm{~min}$, respectively, for BFB, while an optimum $\mathrm{pH} 10,0.1 \mathrm{~g} / \mathrm{L}$ dosage, and settling time of 2 min were recorded for $A B C$, respectively, as presented in ramp plots in Figs. 3, 4 of ESM. It can be deduced from

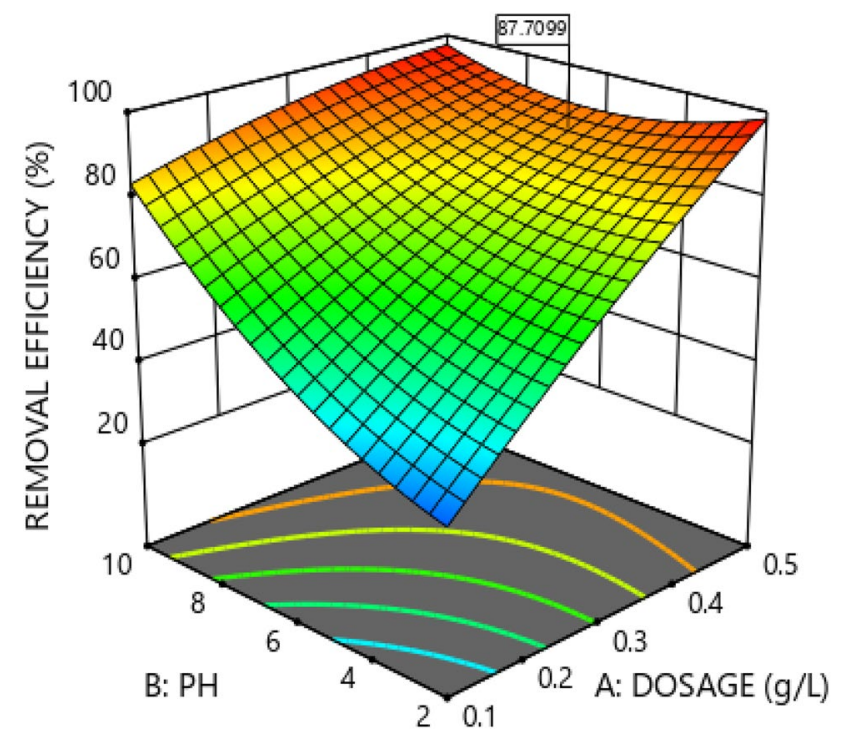

Fig. 1. 3D plot for the BFB coag-flocculation

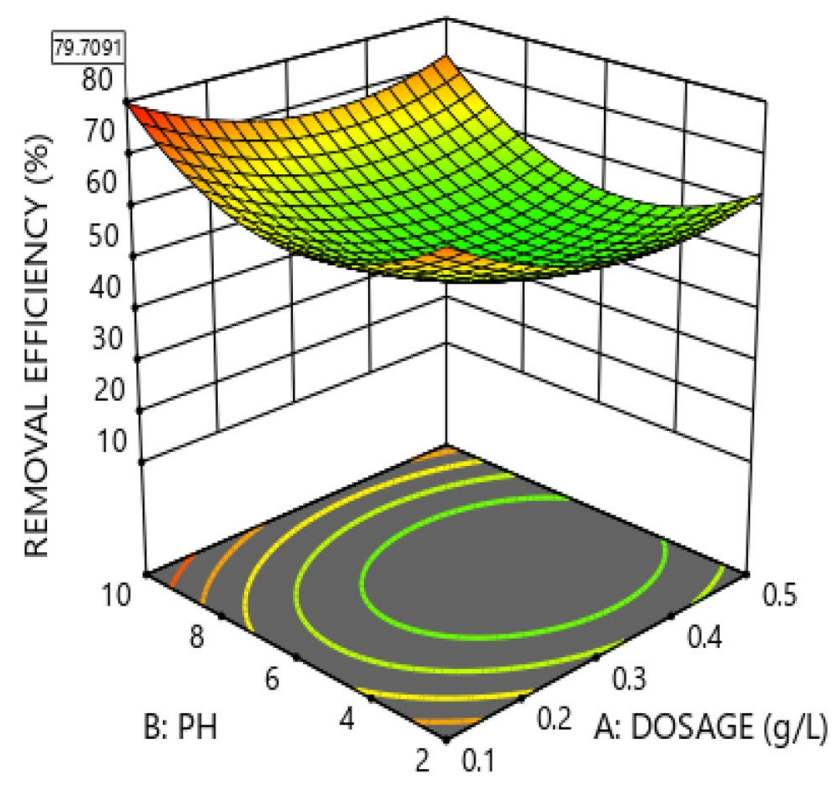

Fig. 2. $3 D$ plot for the $A B C$ coag-flocculation

the results that at optimum operation, the turbidity in the wastewater was reduced from an initial 350 NTU to a value of 42 NTU with $B F B$, while $A B C$ reduced the turbidity from an initial 350 NTU to a residual value of 70 NTU. These values correspond to $88 \%$ of turbidity being removed with $\mathrm{BFB}$, while the $\mathrm{ABC}$-driven coag-flocculation plots $80 \%$ turbidity removal efficiency, respectively.

The CCD following the response surface methodology (RSM) used to develop the 3D surfaces shown in Figs. 1, 2 and 2D contours presented in Figs. 3, 4 confirms the 


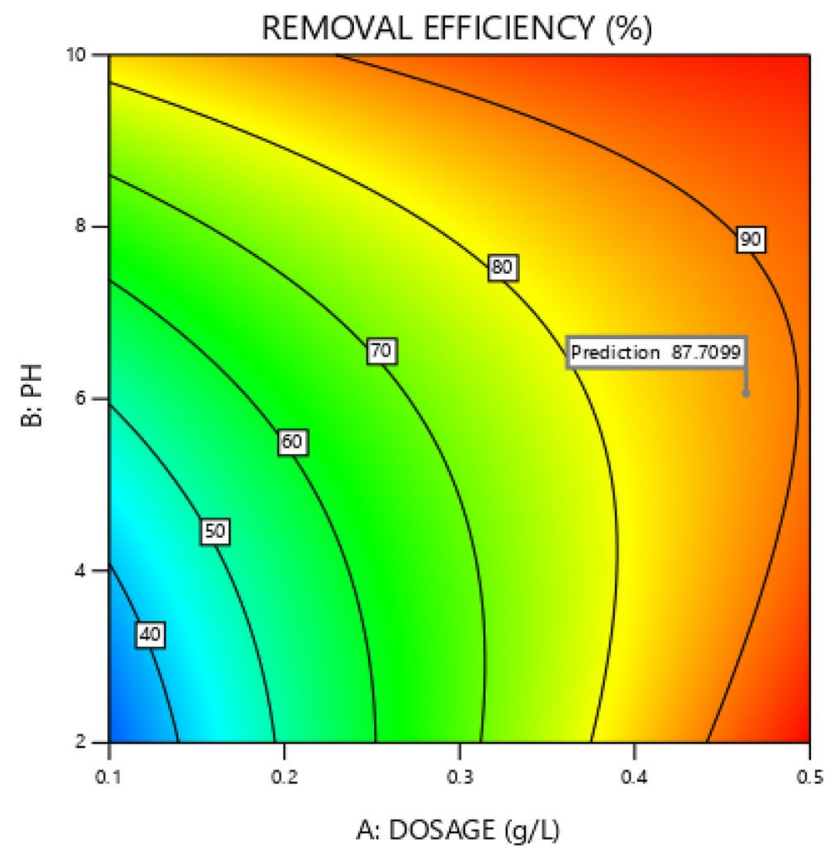

Fig. 3 Contour plot of BFB coag-flocculation

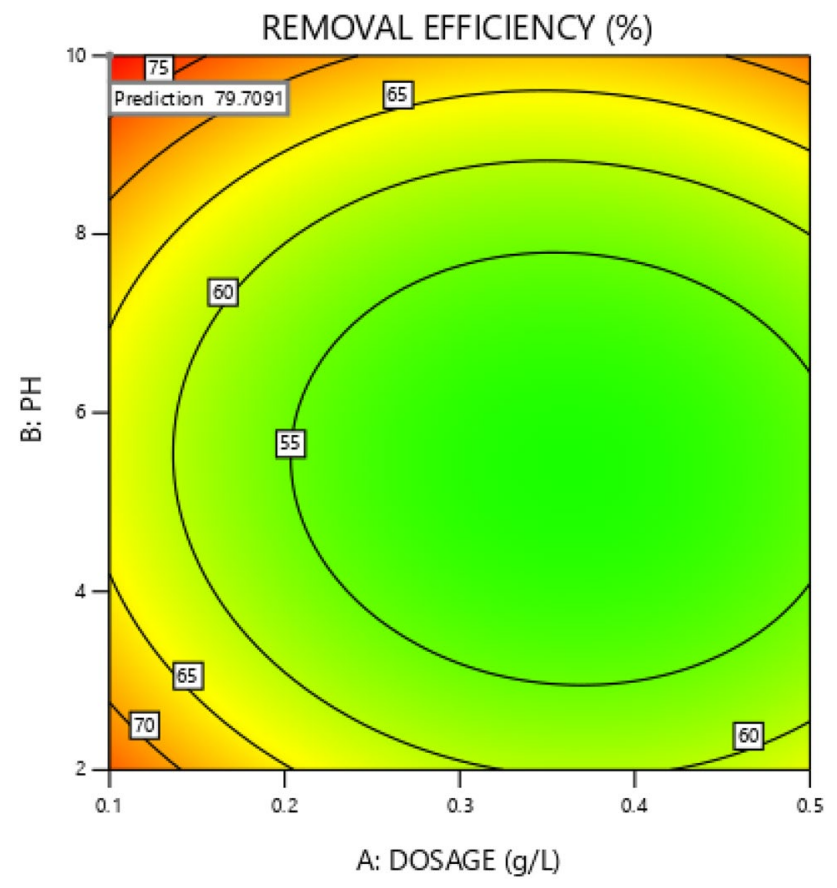

Fig. 4 Contour plot of $A B C$ coag-flocculation

precise location of the optimal points for the $A B C$ - and BFB-driven coag-flocculation process following the interpretations of the quadratic model Eqs. 5 and 6. However, other areas of good performances are well represented by the orientation and elevations of the surfaces and contours of Figs. 3, 4, 5 and 6, respectively.
The respective surface plots in Figs. 5, 6 are drawn for a better comprehension of the coag-flocculation optimization process. The data, depths, and positions of the 3D surfaces serve as a graphical technique showing precisely the functional relationship between the variables and the response parameter (removal efficiency). It explains the interactions of the variables $\mathrm{pH}$ and settling time [13].

However, the plots (Figs. 5, 6) show that two out of the three factors were interdependent, such that there were significant interactive effects between $\mathrm{pH}$ and settling time on the removal efficiency compliance to BFB and $A B C$ coag-flocculation. The curvatures of the $3 D$ surfaces posted the best performance are achieved at an elevation from $\mathrm{pH} 6$ through $\mathrm{pH} 10$ for the BFB-and $\mathrm{ABC}$-driven coag-flocculation. The $\mathrm{pH}$ elevation of the medium is an indication of the strong alignment of the coagulants in the solution. The higher range of $\mathrm{pH}$ attained by the solution was to ensure the complete destabilization of the particles causing turbidity in the wastewater medium.

Figure 6 plots the best performance which was achieved at the $\mathrm{pH}$ elevation of the wastewater from 8 to 10 for $A B C$. At the $\mathrm{pH}$ range (8-10), the turbidity removal efficiency increased appreciably from $63 \%$ through $78 \%$. The increase in $\mathrm{pH}$ of the medium is an indication of an elevation toward a predominantly alkaline solution. An optimum $\mathrm{pH} 10$ was recorded for the $A B C$ coag-flocculation treatment. The optimal $\mathrm{pH}$ result indicated that $A B C$ does not satisfy the EPA standard for industrial wastewater discharge. However, the trough in the 3D surface in Fig. 5 shows contour patterns whose curvatures follow that the areas of best performance of BFB were achieved as $\mathrm{pH}$ increases from 6 through 10, which corresponds to $75 \%$ through $96 \%$ turbidity removal efficiency. Higher degree of removal efficiency was largely dependent on the dosage output of BFB; for the process to be economically viable, an optimal dosage of $0.4 \mathrm{~g} / \mathrm{L}$ was recorded. The optimum $\mathrm{pH}$ of 6 was recorded for BFB. The result obtained confirms that the optimal $\mathrm{pH}$ falls within the range of the EPA acceptable standards for wastewater discharge. Hence, we concluded that the finish water is stable and will neither be corrosive. The optimal $\mathrm{pH}$ was determined to help reduce coagulant wastage and cost of services $[4,27]$.

The surface plots in Figs. 5 and 6 also posted the effect of settling time on the coag-flocculation process. It posted the areas of good performance for the ABC- and BFBdriven coag-flocculation occurred at settling time lesser than $5 \mathrm{~min}$. This result is in agreement with the optimum settling time of 2 min and 4 min reported in Figs. 3, 4 of $E S M$ for the $A B C$ and $B F B$, respectively. The result obtained for the settling time is an indication of a short coag-flocculation period. Hence, we can conclude that the theory of fast coagulation holds for both the BFB- and ABC-driven coag-flocculation, respectively. 


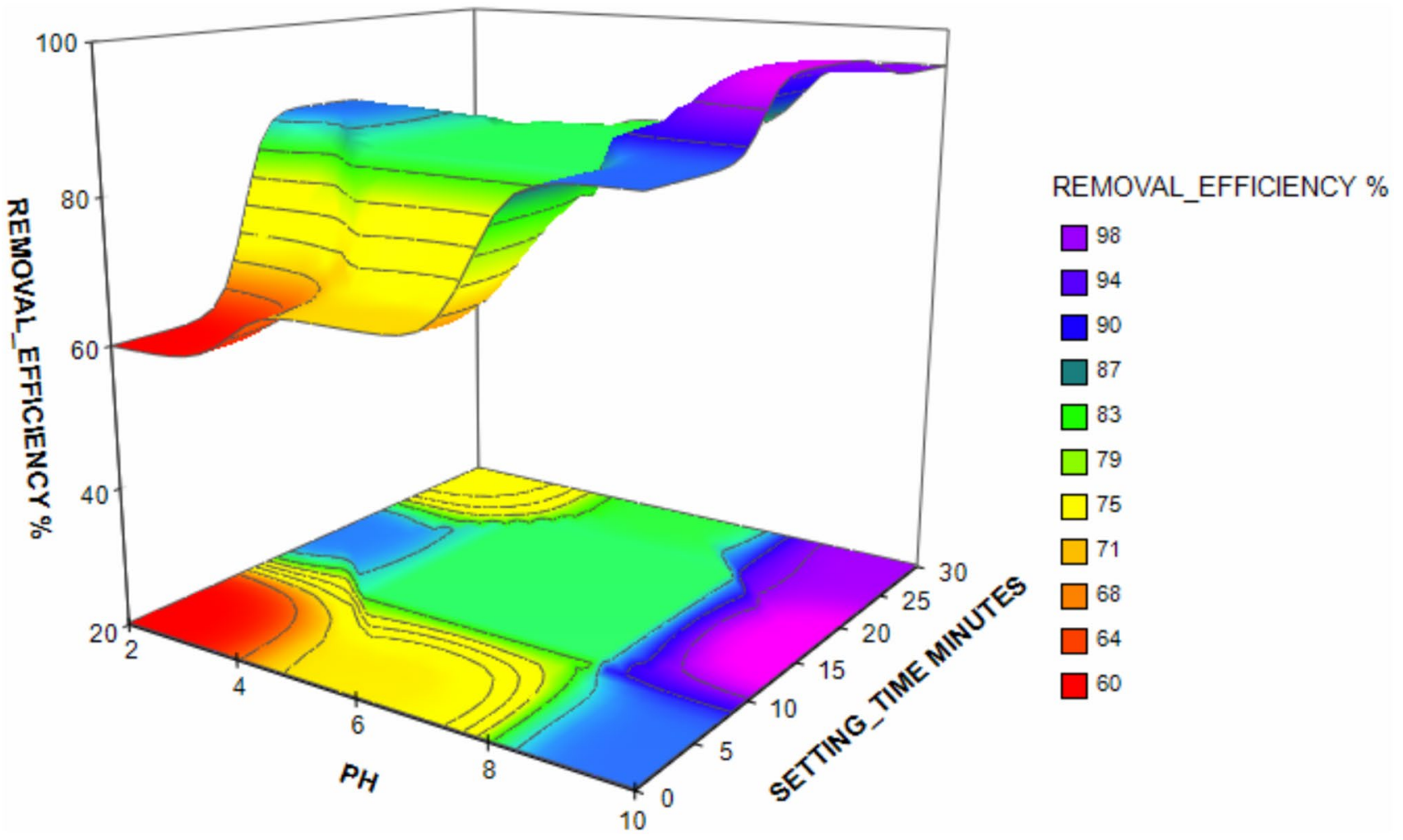

Fig. 5 Surface plot of effect of $\mathrm{pH}$-settling time on removal efficiency for BFB-driven coag-flocculation

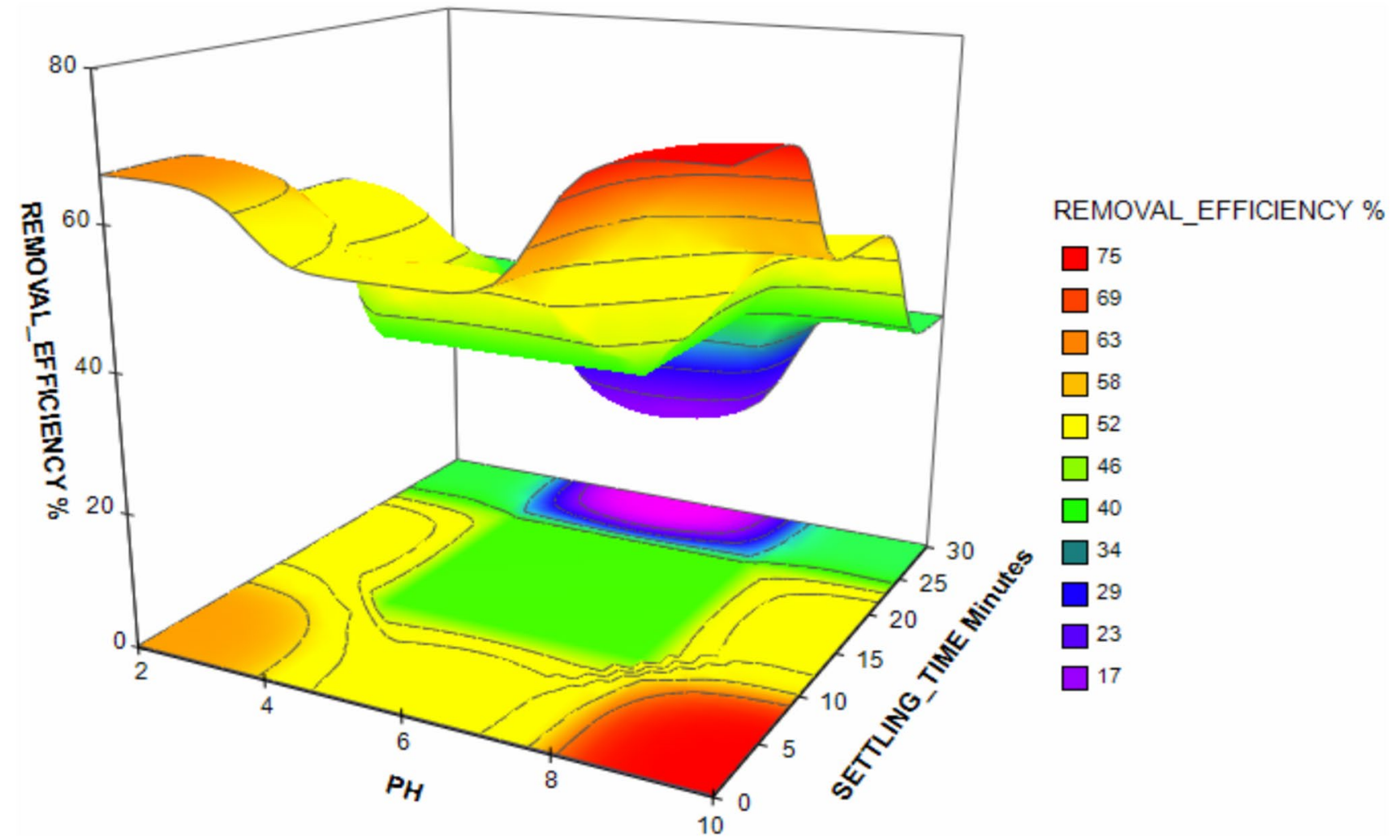

Fig. 6 Surface plot of effect of $\mathrm{pH}$-settling time on removal efficiency for ABC-driven coag-flocculation 
However, the quadratic model developed with the CCD for the optimization process shows that the coagulant dosage has significant main effect on the turbidity removal efficiency. The optimization results presented in Figs. 3 and 4 of ESM show that the optimum dosages were $0.1 \mathrm{~g} / \mathrm{L}$ for $A B C$ and $0.4 \mathrm{~g} / \mathrm{L}$ for $B F B$, respectively. The optimal values of the dosages were considered to be minimal since these values of dosages are less than $0.5 \mathrm{~g} / \mathrm{L}$ [27]. An optimal dosage value lesser than $0.5 \mathrm{~g} / \mathrm{L}$ is an indication that minimal residues were produced during the coag-flocculation period, thus resulting in smaller volumes of residual turbidity. The optimal dosage of the BFB-driven coag-flocculation maintains that there will be little or no scaling in the finish water.

The darker red regions of the underlying contours in Figs. 7 and 8 indicated areas of local maxima corresponding higher quality corresponding to $92 \%$ turbidity removal efficiency with a dosage of $0.5 \mathrm{~g} / \mathrm{L}$ of BFB. The $\mathrm{pH}$ elevation represented in the index contour of Fig. 9 of ESM terminated at a threshold $\mathrm{pH} 10$, and the result was associated with $78 \%$ removal efficiency indicating that $A B C$ requires supplementary alkalinity to further drive the coag-flocculation reaction to completion. Hence, we can conclude from the optimization results that the effectiveness of $A B C$ was not depended on dosage.

\subsection{Coag-flocculation kinetics of turbidity removal for BFB and ABC coag-flocculation}

The kinetics parameters which include the rate constants and the order of reaction were developed following the analogies of the kinetic model Eqs. 7-12. In real practice, empirical evidence shows that the $n$th order of coag-flocculation reactions lies between zero, first-order, pseudofirst-order, or second-order rate laws, such that $(0 \leq n \leq 2)$ $[13,14]$. The model was developed based on the kinetics dependency of the BFB- and ABC-driven coag-flocculation characteristics on the concentration of particles causing turbidity $\left(C_{i}\right)$ with time $(t)$. Thus, the rate equation for the $\mathrm{n}$-th order coag-flocculation can be expressed as:

$-r_{A}=k_{n} C_{i}^{n}$

where $n$ is the order of the reaction at time $(t)$ and $K_{n}$ is the $n$ th-order coag-flocculation rate constant of the reaction. Based on Eq. 7, the rate for coag-flocculation performed for a first-order $(n=1)$ at given reaction time $(t)$ is given thus:

$-r_{A}=K \frac{\mathrm{d} C_{i}}{\mathrm{~d} t}=K C_{i}$

Integrating both sides of Eq. 8 $-\int \frac{\mathrm{d} C_{i}}{\mathrm{~d} t}=\int K_{1} C_{i}$

$\ln C_{i}=K_{1} t-\ln C_{0}$

where $\left(-r_{A}\right)$ is the rate of coag-flocculation reaction, $K_{f}$ is the rate constant for the first-order coag-flocculation expressed in (L/g min), $C_{i}$ are concentrations of particles after treatment expressed in $\mathrm{g} / \mathrm{L}, \mathrm{C}_{0:}$ is the initial concentration of the particles before treatment $(\mathrm{g} / \mathrm{L})$, and $n$ is the order of the coag-flocculation reactions.

The rate constant $\left(K_{\mathrm{f}}\right)$ for a first-order kinetics can be obtained by plotting values of $\left(\operatorname{In} C_{i}\right)$ against time $(t)$, where the slope gives the rate constant $\left(K_{f}\right)$. In most cases, a second-order kinetics rate laws hold for the coag-flocculation treatments of wastewater following the use of organic materials as coagulants [14].

The second-order $(n=2)$ model derivation follows from Eqs. 11 through 12, such that:

$r_{A}=k_{2} C_{i}^{2}=\frac{\mathrm{d} C_{i}^{2}}{\mathrm{~d} t}$

Integrating both sides of Eq. 11, we arrive at:

$\frac{1}{C_{i}}=K_{\mathrm{f}} t+\frac{1}{C_{0}}$

where $K_{2}$ is the constant for the rate of second-order $(n=2)$ coag-flocculation, the initial concentration of the suspended and dissolved particles in the wastewater medium before represented by $C_{0}$ treatment, and $C_{i}$ represents concentrations after coag-flocculation treatment. Expressing the rate constant in terms of other parameter in Eq. 11, and using $K_{f}$ as the reference for $K_{2}$, we arrive at Eq. 12, where $\mathrm{t}$ is the time $(\mathrm{min})$ and $K_{\mathrm{f}}(\mathrm{L} / \mathrm{g} \mathrm{min})$ is the rate constant for the second-order coag-flocculation treatment of the wastewater at optimum conditions. The values of the rate constants of $B F B$ and $A B C$, respectively, were obtained from the evaluation of kinetics trace of the plot in Figs. 11, 12,13 and 14 of ESM, which follows from the graphical evaluations of the concentration $\left(C_{i}\right)$ against time $(t)$ at optimum conditions. The values for the linear correlation coefficients $\left(R^{2}\right)$ were employed to evaluate the level of fits of the experimental data on Eq. 12. From the values of the coag-flocculation rate constants obtained, we can evaluate the clarification efficacy of using $B F B$ to $A B C$ by comparing their rate constants at optimum conditions.

However, Tables $5,6,7$, and 8 of ESM present the values of the rate-related parameters obtained from the analysis of Eq. 12 that strongly influenced the ability of $A B C$ and $B F B$ to remove turbidity from the cosmetic wastewater. Such parameters $\left(K_{\mathrm{f}}\right)$ have direct bearing on design, fabrication, and practical implementation of this 
study. The linear plot (Figs. 11, 12, 13, 14 of ESM) shows that $B F B$ and $A B C$, respectively, obeyed the second-order coag-flocculation rate law $(n=2)$.

The result presented in Table 5 of ESM shows that the rate constant $\left(K_{\mathrm{f}}\right)$ value of $1.3 \times 10^{-3} \mathrm{~L} / \mathrm{g}$ min was obtained at a dosage of $0.5 \mathrm{~g} / \mathrm{L}$, while the rate constant value of $7.7 \times 10^{-4} \mathrm{~L} / \mathrm{g}$ min was obtained at $0.4 \mathrm{~g} / \mathrm{L}$ dosage for the BFB-driven coag-flocculation kinetics at optimum $\mathrm{pH}$. The lowest rate constant $\left(K_{\mathrm{f}}\right)$ value of $1 \times 10^{-4} \mathrm{~L} / \mathrm{g}$ min was obtained at a dosage of $0.3 \mathrm{~g} / \mathrm{L}$ at $\mathrm{pH} 6$ and settling time of $4 \mathrm{~min}$, respectively. From the trend of values obtained for the coag-flocculation kinetics, it was observed that at optimum $\mathrm{pH} 6$, the $K_{\mathrm{f}}$ values increased appreciably with the increase in dosage of BFB added to the water medium. Higher values of rate constant were obtained with an increase in dosages of BFB as the $\mathrm{pH}$ of the solution increased from 6 through 10 . The kinetics result confirms that $\mathrm{pH}$ and dosage are the most important factors that influenced the clarification efficiency of BFB. Higher rate constant was obtained as $\mathrm{pH}$ increases from 6 to 10 , and dosage from 0.3 to $0.5 \mathrm{~g} / \mathrm{L}$. The $\mathrm{pH} 10$ does not satisfy the EPA standard for wastewater discharge, and $0.5 \mathrm{~g} / \mathrm{L}$ dosage outputs for BFB are an indication of coagulant wastage. Thus, we concluded that at $\mathrm{pH} 10$, the finish water may cause scaling, with the same potential to blind filters leading to increasing operational cost. The optimum dosage $0.4 \mathrm{~g} / \mathrm{L}$ of BFB yielded high $K_{\mathrm{f}}$ value of $7.7 \times 10^{-4}(\mathrm{~L} / \mathrm{g} \mathrm{min})$ at the optimal pH 6 . Hence, we conclude from the kinetics result that the efficacy of the blends of fishbone satisfied the EPA standard for industrial wastewater discharge. Thus, the kinetics result is in obvious agreement with the optimization result for BFB obtained from the RSM.

The kinetics results obtained for the $A B C$ driven coag-flocculation plot the highest $K_{f}$ value of $3.4 \times 10^{-4} \mathrm{~L} / \mathrm{g} \mathrm{min}$ at $0.1 \mathrm{~g} / \mathrm{L}$ dosage. The lowest $\left(k_{\mathrm{f}}\right)$ value of $5 \times 10^{-5} \mathrm{~L} / \mathrm{g}$ min was obtained at $0.3 \mathrm{~g} / \mathrm{L}$ dosage of $A B C$ at the optimum $\mathrm{pH} 10$ and settling time of $2 \mathrm{~min}$. The $K_{\mathrm{f}}$ values decreased from $5 \times 10^{-5} \mathrm{~L} / \mathrm{g}$ minto $3.4 \times 10^{-4} \mathrm{~L} / \mathrm{g}$ min with an increase in dosage of $A B C$ added to the water medium. The highest rate constant $K_{\mathrm{f}}$ value of $\mathrm{ABC}$ was obtained at optimum dosage $0.1 \mathrm{~g} / \mathrm{L}, \mathrm{pH} 10$, and settling time of $2 \mathrm{~min}$. Thus, the kinetics result obtained for $A B C$-driven coag-flocculation confirms the optimization results obtained with the RSM.

Figure 7 is used to compare the rate constants of both coagulants at their optimum $\mathrm{pH}$ and dosage. The plot shows that the rate constant $K_{\mathrm{f}}$ of the BFB-driven coag-flocculation surpassed rate value of $A B C$ at their optimum conditions. Thus, we concluded that the organic coagulant aligned well with the solution at the optimum $\mathrm{pH} 6$ and was more effective than aluminum sulfate coagulant used for the treatment of cosmetics wastewater at their optimum conditions. We also concluded that since

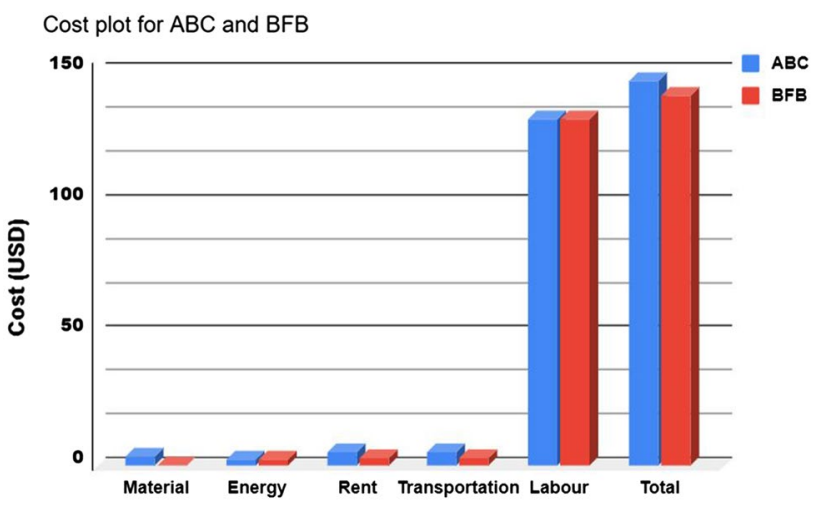

Fig. 7 Coag-flocculation rate constant for $B F B$ and $A B C$ at optimum $\mathrm{pH}$

the $\mathrm{pH}$ terminates at 10 , an increase in dosage of $\mathrm{BFB}$ from 0.4 to $0.5 \mathrm{~g} / \mathrm{L}$ is an indication that the alkalinity of the solution was well preserved. As such, BFB can function as a coagulant aid that can be used to raise alkalinity of any wastewater whose alkalinity is reported to be greater than $100 \mathrm{mg} / \mathrm{L}$, and acidity lower than $20 \mathrm{mg} / \mathrm{L}$. Also, the inability of $A B C$ to drive the stability below $\mathrm{pH} 10$ might be due to excess negative charges of the particles of the water medium. Consequently, $\mathrm{ABC}$ requires further acidity to necessitate the $\mathrm{pH}$ depression below 10 .

Considering the viability of $A B C$ in terms of the dosage required to induce coag-flocculation, hosting the efficacy of $0.4 \mathrm{~g} / \mathrm{L}$ dosage of $B F B$ over $0.1 \mathrm{~g} / \mathrm{L} \mathrm{ABC}$ at optimal conditions will depend on the cost-benefit analysis of both coagulants. This includes the cost of maintaining a pH between 6 and 8 throughout the coag-flocculation treatment process in order to satisfy the EPA standards for industrial wastewater discharge.

\subsection{Cost-benefit analysis of the present study}

The present proposal was to test and implement blends of fishbone (BFB) as a natural coagulant-flocculants aid or as a substitute or to be used as hybrids with other conventional chemicals for the coag-flocculation treatments of wastewater. Although the $\mathrm{pH}$ output for BFB satisfied the EPA standard for industrial wastewater discharge at an optimum dosage of $0.4 \mathrm{~g} / \mathrm{L}$, the small amount of dosage loading of $0.1 \mathrm{~g} / \mathrm{L}$ reported for $A B C$ is considered to be very viable economically. A maximum value of $96 \%$ threshold turbidity removal was recorded with BFB at a $\mathrm{pH}$ of 10 , setting time of $5 \mathrm{~min}$, and a dosage of $0.5 \mathrm{~g} / \mathrm{L}$. From the results obtained from Figs. 2 and 4, the threshold removal efficiency of $80 \%$ was reported with $A B C$ under the same conditions of $\mathrm{pH}$ and settling time. The wastewater treatment and respective cost requirements are more or less similar for both coagulants cosmetic to be 
used in wastewater treatment plants. However, the major difference will be concerned for the industrial production outputs of the coagulants.

The cost-benefit analysis was evaluated by Eq. 13 to determine the cost for energy consumption based on instrumentation requirements for the $B F B$ and $A B C$ coag-flocculation process. The energy consumption $E_{c}$ equation is given by:

$E_{\mathrm{C}}=P_{\mathrm{D}}\left(a \times t \times C_{\mathrm{C}}\right)$

where $P_{\mathrm{D}}$ is the power consumed by the device in (KW), $a$ is the load factor, $t$ is the time in $(\mathrm{Hr})$, and $C_{\mathrm{C}}$ is the cost per consumption. The values of $a=1$ are used when the equipment was used at full-load module, and $a=0.5$ for half-load mode.

The raw material cost prices for this study were obtained from the local vendors. It should be noted here that the variability of the coagulants and operational cost depends on the quantity of the final results of the analysis. The organic coagulant was predominantly made from varieties of fishbone taking into consideration the availability of the raw materials needed for the commercial production. The coagulant comprises of fishbone of tilapia which is relatively common, and catfish is reported in abundant supply in the West Africa and Asian region, while salmon can be found in sufficient supply across parts of the globe. The cost remediation is calculated and translated to the US Dollar (USD).

The present cost analysis took into account the market prices, as well as prices provided by vendors across the world. The raw materials took into account multiple market prices for other coagulants used specifically for turbidity removal from cosmetics wastewater. The electricity costs per KWH (kilowatt hour) used for this study are based on the average price in Nigeria for the year 2020. An estimated $0.107 \$ / K W H$ for businesses included all components of electricity bills such as the cost for power, distribution, and taxes calculated as an average annual level of electricity consumption. This price was retrieved from the Benin Electrical Distribution Company (BEDC) [32]. The total electricity cost for this project was calculated and estimated to $2.48 \mathrm{USD} / \mathrm{kg}$ of coagulant. The raw material cost for alum bought from a chemical vendor, Kincel Excel International Nigeria Limited, was 1.75 USD per kilogram.

Labor cost consisted of compensations for researchers participating in the project, with the addition of taxes and benefits. For the purpose of this study, the personnel requirements and synthesis process comprised of one postgraduate researcher student, and one research supervisor working for 1 workday (i.e., $3 \mathrm{~h}$ ). The average wages of the personnel were assessed based on the cost of contract service cost information, which maintains a rich database with employee wages per company depending on the position.

Table 9 of ESM is drawn to calculate the recipe cost, gathering all appropriate information presented with relative structures. Energy cost was calculated as 2.48 USD. Therefore, the total cost of production was estimated 140.98 USD per kilogram for this proposal including the cost of transportation to the site of remediation.

Total cost: This is the sum of the direct and indirect cost.

Opportunity Cost: This is the difference in the return of the forgone option and the chosen. Mathematically, it can be seen as:

$\mathrm{OC}=F_{0}-R_{0}$

where $F_{0}=$ Return on best forgone option; in this case ,we are considering $\mathrm{ABC}=146.48 \mathrm{USD}$ and $R_{0}=$ Return on chosen option blends of fishbone (BFB) $=140.98$ USD.

Hence, opportunity cost $(O C)=146.48-140.98=5.5$ USD.

In this case, the benefit of using BFB will save 5.5 USD based on this work. The diagrammatical representation of the cost benefits remediation is presented in Fig. 8. The result of the cost comparison of blends of fishbone (BFB) to alum $(A B C)$ plots that it is slightly higher to operate the coagulation-flocculation treatment of the cosmetic wastewater at optimum conditions using $A B C$ for turbidity removal than BFB.

\subsubsection{Cost of potential risks}

There is little or no cost associated with potential risk as the BFB is biodegradable and environmentally friendly. The regulatory risk is very minimal because it does not pose any hazardous threat to lives. In this cost benefit analysis, we are comparing the cost of using blended fish bone (BFB) as an alternative to alum which is a widely used coagulant. Aside the decrease in water $\mathrm{pH}$ which increases the alkalinity of the water and the possible introduction of

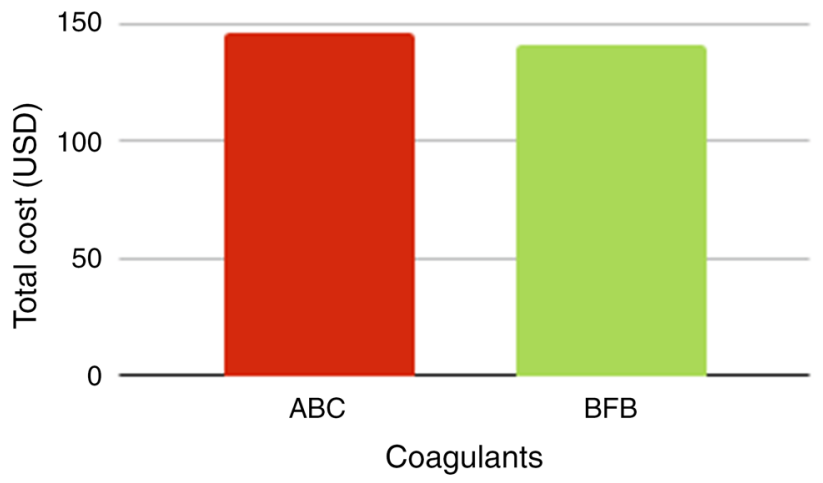

Fig. 8 Bar chart showing the total cost of $A B C$ and BFB coagulants 
Table 3 Comparison of ESC removal efficiency at optimal conditions

\begin{tabular}{lllll}
\hline Parameters & $\begin{array}{l}\text { Blends of fish- } \\
\text { bone (present } \\
\text { study) }\end{array}$ & Fishbone (reference 22) & Fishbone (reference 33) & Fishbone (reference 23) \\
\hline Water medium & $\begin{array}{c}\text { Cosmetic indus- } \\
\text { trial wastewater }\end{array}$ & Synthetic wastewater & Microalgae species & Dye aqueous system \\
Removal efficiency (\%) & 88 & 75 & 92 & 24.76 \\
$\begin{array}{l}\text { Dosage of fishbone coagu- } \\
\text { lants (g/L) }\end{array}$ & 0.4 & 2.5 & 1.5 & 0.07 \\
pH & 6 & 4 & 2 & - \\
Settling time (mins) & 4 & 30 & 35 & - \\
Stirring speed (rpm) & 1000 & 200 & 250 & 3000
\end{tabular}

dissolved toxic aluminum compounds, the intangible cost of no environmental impact of $\mathrm{BFB}$ is a major factor that cannot be quantified. This is a major cost benefit over a period of time in terms of return on investment.

\subsection{Comparison of the result of the present study with other research work}

To summarize the efficacy of BFB, we compared the results from this study with the results of other authors referenced in this work. Table 3 gives a summary of the comparison.

From Table 3, an optimal $\mathrm{pH}$ equal to 6 recorded for $\mathrm{BFB}$ is in wide contrast with the optimum $\mathrm{pH}$ results of fishbone used by the other researcher, and thus, we concluded that the blends of fishbone yielded better performance than unblended fish bones used by the other researchers in terms of the $\mathrm{pH}$ satisfying the EPA standard for wastewater discharge. Also, when compared with the work of the other authors, the $\mathrm{pH}$ result shows that fishbones are viable sources for wastewater treatments. This report goes a long way to justify the efficacy and potentials of BFB for satisfying the World Health Organization (WHO) $\mathrm{pH}$ guidelines (6-8) for wastewater discharge [5, 10].

The table further emphasizes the difference in stirring rate, and removal efficiencies of fishbone as it varied between references [23] and the present work, and those of references [22,33], respectively. The results show a wide disparity in their removal efficiency with the variations in stirring speeds. We reasoned that the results varied due to the differences in the compositions of the water medium and their characteristics. The comparisons of the results from the works of references $[22,33]$ depict that the stirring speeds have little or no direct bearing on their removal efficiencies; rather the coag-flocculation shear characteristics between the particles and the specialty index of the coagulant alignment with the wastewater are the determinant factor that greatly influenced the removal efficiency $[9,22,23,24,27,34]$.
The difference in the properties of the water medium will determine the quantity of coagulants applied at the optimum conditions. The optimal dosage of $0.4 \mathrm{~g} / \mathrm{L}$ achieved for the present work makes BFB a viable coagulant when compared with the referenced results. It has also proven that BFB posted higher removal efficiency corresponding to $96 \%$ when compared to unblended fish bones used by the other researchers when used in an industrial environment. The cost-benefit analysis compared with the results for alum as applied to the present work further elaborates the efficacy and importance of BFB coagulant in the treatment of cosmetic wastewater systems.

\section{Conclusion}

The conclusions drawn from the research findings on the coagulation-flocculation treatment of cosmetic wastewater include that blends of fishbone (BFB) were proven to be more efficient than aluminum-based coagulant ( $A B C$ ) in terms of $\mathrm{pH}$. The output of the blends of fishbone satisfied the $\mathrm{pH}$ standard of the EPA for industrial wastewater discharge, while alum does not. The best performance of fishbone was found to occur at an optimum dosage with minimal potential to blind filters, short coag-flocculation time, scaling was reduced and energy conserved. It effectively reduces high turbidity in cosmetics wastewater to small residual volumes at short periods of settling time. The organic material was confirmed as a viable coagulant-flocculants aid showing strong capacity to function best with alum. We concluded further from the cost remediation analysis that it is economically viable to treat wastewater with low acidity and high alkalinity using blends of fishbone at high stirring rate. The reused material was proven to save cost compared to alum for water treatment processes $[35,36]$.

\section{SN Applied Sciences}




\section{Compliance with ethical standards}

Conflict of interest The authors declare that they have no conflicts of interest.

Open Access This article is licensed under a Creative Commons Attribution 4.0 International License, which permits use, sharing, adaptation, distribution and reproduction in any medium or format, as long as you give appropriate credit to the original author(s) and the source, provide a link to the Creative Commons licence, and indicate if changes were made. The images or other third party material in this article are included in the article's Creative Commons licence, unless indicated otherwise in a credit line to the material. If material is not included in the article's Creative Commons licence and your intended use is not permitted by statutory regulation or exceeds the permitted use, you will need to obtain permission directly from the copyright holder. To view a copy of this licence, visit http://creativecommons. org/licenses/by/4.0/.

\section{References}

1. Sample PDF documentation on "Global Cosmetics Products Market Top Country Data" (2020). http://www.360marketupdates. comsample/12884489, http:www.wfmj.com.

2. Google documents New York. Published by Zion market research New York, (2018). http://www.zionmarketresearch. com/sample/cosmetic-products-market.

3. Sample PDF document "Cosmetic and skin care products Global Industry perspective, Comprehensive analysis and Forecast (2018): 2017-2024"Report code: ZMR-893, pp 1-160. http://www.zionmarketresearch.com/repor/cosmetic-produ cts-market.

4. Recommended Standards for Wastewater Facilities: Policies for Design, Review and Plans for Wastewater Collections and Treatments Facilities (2014): Health Research, Inc, Health Education Service Division. http://www.healthresearch.org/store/ ten-state-standards.

5. EPA guidelines for water quality-based decisions (1991) The TMDL Process Doc. (1991); No. EPA 440/4-91-001

6. Environmental Protection Agency (EPA) (1999) Quality-Based Decisions. The TDML Process Doc. No EPA 440/4-91.001: TDML Proc. Doc., 1999

7. Malik QH (2018) Performance of alum and assorted coagulants in turbidity removal of muddy water. J Appl Water Sci 40:1-10

8. Usefi S, Asadi-Ghalhari M (2019) Optimization of turbidity removal by coagulation and flocculation process from synthetic stone cutting wastewater. Int J Energy Water Resour 3(11):3341. https://doi.org/10.1007/s42108-019-00010-2

9. Enerst $\mathrm{E}$, Onyeka O, David N, Blessing O (2017) Effect of $\mathrm{PH}$ dosage, temperature and mixing speed on the efficiency of water melon seed in removing the turbidity and colour of Atabong River, Akwa-lbom State, Nigeria. Int J Adv Eng Manag Sci (IJAEMS) 2454-1311

10. WHO, UNEP, GEMS (1989) Global freshwater quality. Alden Press, Oxford

11. Tran NVN, Yu QJ, Nguyen TP, Wang S-L (2020) Coagulation of chitin production wastewater from shrimps scraps with byproduct from chitosan and chemical coagulant polymers. MDPI Academic Open Access Publishing. 126072020 (2020): 20

12. Khan $A H$, Khan NA, Ahmed $S$, Dhingra $A$, Singh $C P$, Khan $S U$, Mohammadi AA, Changani F, Yousefi M, Alam S, Vambol S, Vambol V, Khursheed A, Ali I (2020) Application of advanced oxidation processes followed by different treatment technologies for hospital wastewater treatment. J Clean Prod 269:122-411

13. Menkiti MC, Nnaji PC, Onukwuli OD (2009) Coag-flocculation kinetics and functional parameters response of periwinkle shell coagulant (PSC) to $\mathrm{PH}$ variation in organic rich coal effluent. J Natl Sci 7(6):1-18

14. Nnaji PC, Okoye CC, Umeuzuegbu JU (2020) Efficiency of Luffa cylindrica and Muccuna Sloaneai seeds in dye removal: a new approach. World Sci News Int J 2392-2192:84-201. https://doi. org/10.1007/s13201-018-0662-5

15. Greenberg LS, Eaton AD Standard methods for the examination of water and wastewater, 20th ed. APHA, USA

16. Farajnezhad $\mathrm{H}$, Gharbani $\mathrm{P}$ (2012) Coagulation treatment of wastewater in petroleum industry using poly aluminum chloride and ferric chloride. IJRRAS 13(1)

17. Iwuozor KO (2019) Prospects and challenges of using coagulation and flocculation method in treatment of effluents. Adv J Chem 2(2):105-127. https://doi.org/10.29088/SAMI/AJCA. 2019.2.105127

18. Lourenco A, Arnold JL, Gamela JAF, Cayre OJ, Rasterio MG (2018) Anionic poly-electrolytes synthesized" an aromatic-free-oils process for application as flocculants in dairy-industry effluent treatment. J Ind Eng Chem Res 57(49):16884-16896. https://doi. org/10.1021/acs.iecr.8b03546

19. Subasinghe R (2017) FAO fisheries and aquaculture circular FIAA/C1140 (En): world aquaculture production 2015. A brief overview: (2017). Yearbook of Fisheries Statistics. http://www. fao.org

20. United Nations Food and Agriculture: Food and Agriculture Organization of the United Nation, 2002. . No 1774. http://www. fao.org

21. Rahman NS, Yhaya MF, Azahari B, Ismail WR (2018) Ultilization of natural cellulose fibres in wastewater treatment. Springer, New York

22. Ebrahimi A, Arami M, Bahrami H, Pajootan E (2013) Fish bone as a low-cost adsorbent for dye removal from wastewater: response surface methodology and classical method. J Environ Model Assess. https://doi.org/10.1007/s10666-013-9369-z

23. Mu Y, Saffarzadeh A, Shimaoka T (2016) Feasibility of using natural fishbone Apatite for removal of $\mathrm{Pb}$ from municipal solid waste inceneration (MSWI) fly ash. J Procedia Environ Sci J 31:345-350. https://doi.org/10.1016/j.provenv.2016.02.046

24. Kan CC, Huang C-P (2002) Coagulation of high turbidity water: the effects of rapid mixing. J Water Supply Res Technol 51:77-85

25. Othmani B, Rasteiro MG, Khadhraoui M (2020) Towards green technology: a review on some efficient model plant-based coagulants/flocculants for fresh-water and wastewater remediation. J Clean Water Technol Environ Policy 22:1025-1040

26. Muruganandam L, Saravana Kumar MP, Jena A, Gulla S, Godhwani B (2017) Treatment of wastewater by coagulation and flocculation using biomaterials. In: IOP conference series: materials science and engineering, vol 263, p 032006. https://doi.org/ 10.1088/1757-899X/263/3/032006

27. Greville AS (1997) How to select a chemical coagulant and flocculants. In: Alberta waste \& wastewater operators association 22nd annual seminar

28. Pivokonsky M, Naceradska J, Brabenec T, Novotna K (2015) The impact of interactions between algea organic matter and himic substances on coagulation. PubMed Water Res 84:278-284

29. Tetteh EK, Rathilal S (2019) Application of organic coagulants in water and wastewater treatment. Inter-open 4. https://doi.org/ 10.5772/Inter-open.84556

30. Feng Y, Chu Z, Man L, Hu Y, Zhang C, Yuan T, Yang Z (2019) Fishbone-like polymer from green cationic polymerization of methyl 
eleostearate as bio-based nontoxic PVC plasticizer. ACS Sustain Chem Eng 7(23):18976-18984

31. Vivian C, Mohan Dhas S, Ashwin G (2019) Evaluation of biobased fibers for treatment of wastewater from textile industry. Int J Innov Technol Explor Eng 8(8):2278-3075

32. New tariff rate and customers classification-BEDC ELECTRICITYTARRIF www.bedcpower.com/new-electricitytariff-rate-2, February (2016): internet material

33. Okey-Onyesolu CF, Onukwuli OD, Ejimofor MI, Okoye CC (2020) Kinetics and mechanistic analysis of particles decontamination from abattoir wastewater (ABW) using novel Fish Bone Chitoprotein (FBC). Elsevier Publication Ltd, New York. https://doi.org/ 10.1016/j.heliyon.2020.e04468
34. Bayar S, Yildiz YS, Erdem A, Irdemez S (2011) Effect of stirring speed and current density on removal efficiency of poultry slaughter house wastewater by electrocoagulant method. Desalination 280:103-107

35. Abidemi BL, Adekunle O, Temitope A, Joshua O, Rachael A (2019) Treatment technology of wastewater from cosmetic industry a review. Int J Chem Bio Mol Sci 4(4):69-80

36. Cui H, Having X, Yu Z, Chen P, Cao X (2020) Application Progress of enhanced coagulation in water treatment. RSC Adv 34

Publisher's Note Springer Nature remains neutral with regard to jurisdictional claims in published maps and institutional affiliations. 